Chronic Obstructive Pulmonary Diseases: Journal of the COPD Foundation

\author{
Original Research
}

\title{
Overall and Cardiovascular Safety of Aclidinium Bromide in Patients With COPD: A Pooled Analysis of Six Phase III, Placebo- Controlled, Randomized Studies
}

Kenneth R. Chapman, MD ${ }^{1}$ Ekkehard Beck, $\mathrm{MD}^{2}$ Daniel Alcaide, $\mathrm{MSc}^{3}$ Esther Garcia Gil, $\mathrm{MD}^{4}$

\begin{abstract}
Background: Aclidinium bromide, an $\mathrm{M}_{3}$-receptor-selective, twice-daily (BID), long-acting muscarinic antagonist, is rapidly hydrolyzed in human plasma, resulting in low systemic exposure and urinary excretion. We evaluated the overall and cardiovascular (CV) safety of aclidinium in patients with moderate to severe chronic obstructive pulmonary disease (COPD) by pooling data from 6 randomized, double-blind, placebo-controlled, parallel-group studies of $\geq 1$ month's duration.

Methods: Patients were current/former smokers aged $\geq 40$ years with no history of clinically significant CV conditions. Treatment was administered (morning and evening) via Genuair ${ }^{\mathrm{TM}} /$ Pressair. ${ }^{\circledR \mathrm{a}}$ Adverse events (AEs), major adverse CV events (MACE), cardiac and cerebrovascular AEs, and serious AEs (SAEs) were analyzed.

Results: The pooled population included 2781 patients (aclidinium: $\mathrm{n}=1529$; placebo: $\mathrm{n}=1252$ ). The incidence of AEs was similar with aclidinium (53.5\%) and placebo (55.4\%), as was the incidence of cardiac (aclidinium: 5.0\%; placebo: $4.4 \%$ ) and cerebrovascular (aclidinium: 0.4\%; placebo: 0.5\%) events. The incidence of MACE was low (AEs: 0.7\%; SAEs: 0.5\%) and comparable between groups. The incidence of cardiac and cerebrovascular events was similar for patients with CV risk factors with aclidinium and placebo (rate ratio [RR] [95\%confidence interval $(\mathrm{CI})]=1.01[.074,1.39])$. In patients with mild to severe renal impairment, the incidence of cardiac events was similar between groups (RR $[95 \% \mathrm{CI}]=0.87[0.56,1.36])$.

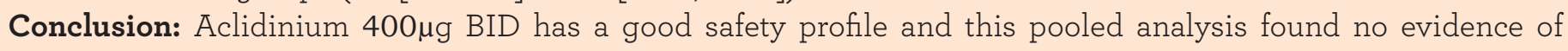
increased CV or cerebrovascular risk compared with placebo in patients with moderate to severe COPD. Further studies are needed in high-risk patients.
\end{abstract}

\begin{abstract}
Abbreviations: twice daily, BID; cardiovascular, CV; chronic obstructive pulmonary disease, COPD; adverse event, AE; major adverse cardiovascular event, MACE; serious adverse event, SAE; rate ratio, RR; confidence interval, CI; long-acting muscarinic antagonist, LAMA; Global initiative for chronic Obstructive Lung Disease, GOLD; dry-powder inhaler, DPI; Understanding Potential Long-term Impacts on Function with Tiotropium, UPLIFT trial; TIOtropium Safety and Performance in Respimat, TIOSPIR trial; chronic kidney disease, CKD; fixed-dose combination, FDC; once daily, QD; forced expiratory volume in 1 second, FEV1; Standardized MedDRA Queries, SMQ; preferred term, PT; myocardial infarction, MI; system organ class, SOC; angiotensin-converting enzyme, $\mathbf{A C E}$; calcium ion, $\mathbf{C a}^{\mathbf{2 +}}$; standard deviation, SD

Funding Support: The studies included in this pooled analysis were funded by Almirall S.A., Barcelona, Spain and Forest Laboratories LLC, a subsidiary of Actavis PLC, New York, New York. The pooled analysis was funded by Almirall S.A., Barcelona, Spain.

Date of Acceptance: October 30, 2015

Citation: Chapman KR, Beck E, Alcaide D, Garcia Gil E. Overall and cardiovascular safety of aclidinium bromide in patients with COPD: A pooled analysis of six phase III, placebo-controlled, randomized studies. Chronic Obstr Pulm Dis (Miami). 2016;3(1):435-445. doi: http// dx.doi.org/10.15326/jcopdf.2015.3.1.0148
\end{abstract}

1 Asthma \& Airway Centre, University Health Network, Toronto Western Hospital, Toronto, Ontario, Canada

2 Institut für Gesundheitsförderung $\mathrm{GmbH}$, Rüdersdorf, Germany
3 R\&D Centre, Almirall S.A., Barcelona, Spain

4 R\&D Centre, AstraZeneca PLC, Barcelona, Spain 


\section{Address correspondence to:}

Professor Kenneth R. Chapman

Director, Asthma \& Airway Centre, University Health Network,

Toronto Western University

Room 7-451 East Wing, 399 Bathurst Street,

Toronto, Ontario M5T 2S8

Phone: 1-416-603-5499

Fax: 1-416-603-3456

Email: kchapman@ca.inter.net

\section{Keywords:}

aclidinium bromide; chronic obstructive pulmonary disease; safety

\section{Introduction}

International guidelines recommend the use of longacting muscarinic antagonists (LAMAs) as a first-choice treatment option for patients with chronic obstructive pulmonary disease (COPD) who are in Global initiative for chronic Obstructive Lung Disease (GOLD) Groups B, $C$ and D. ${ }^{1}$ However, the results of several meta-analyses have highlighted concerns surrounding the safety particularly cardiovascular (CV) safety - of the LAMA tiotropium when delivered via mist inhaler (Respimat ${ }^{\circledR}$ Soft Mist ${ }^{\mathrm{TM}}$ ) as a therapy for COPD. ${ }^{2-4}$

A meta-analysis of 5 randomized controlled trials $(n=6522)$ indicated a $52 \%$ increased risk of all-cause mortality associated with tiotropium via mist inhaler compared with placebo. ${ }^{4}$ Similarly, a mixed-treatment comparison meta-analysis $(n=52,516)$ found an increased risk of all-cause mortality associated with tiotropium via mist inhaler compared with placebo and other treatments, including tiotropium via drypowder inhaler (DPI) (HandiHaler $\left.{ }^{\circledR}\right) .{ }^{2}$ Whilst the increased risk of all-cause mortality with tiotropium via mist inhaler was particularly pronounced for the unlicensed $10 \mu \mathrm{g}$ dose compared with the licensed $5 \mu \mathrm{g}$ dose, there was a twofold increase in the risk of $\mathrm{CV}$ death compared with placebo, irrespective of dose. ${ }^{2}$ In contrast, for patients randomized to tiotropium via DPI in the 4-year Understanding Potential Long-term Impacts on Function with Tiotropium (UPLIFT) trial, there was a trend towards reduced mortality compared with placebo. ${ }^{5}$ TIOtropium Safety and Performance in Respimat (TIOSPIR), a large $(\mathrm{n}=17,135)$, randomized safety study intended to address the question of LAMA safety, did not include a placebo arm and therefore only reported no difference in mortality or exacerbation rate among tiotropium formulations. ${ }^{6}$

Given that CV comorbidities are common in patients with $\mathrm{COPD},{ }^{7,8}$ further investigation of the CV safety of tiotropium and other LAMAs is essential. Other comorbidities may also need to be taken into account when considering a treatment strategy. For example, there is some evidence that patients with chronic kidney disease (CKD) may be at increased risk of mortality when using tiotropium mist inhaler compared with patients with normal kidney function. ${ }^{9,10}$

Aclidinium bromide, another LAMA for the treatment of COPD, has high affinity for all 5 human muscarinic receptor subtypes $\left(M_{1}-M_{5}\right)$, but a residence time at $M_{3}$ that is 6 times longer than that at $M_{2}$, and a half-life for $M_{2}$ that is 3.22 times shorter than tiotropium. ${ }^{11}$ This kinetic selectivity may reduce the potential for non-pulmonary adverse events associated with blockade of $\mathrm{M}_{2}$. More significantly, and distinct from other commonly used antimuscarinic bronchodilators, aclidinium is rapidly hydrolyzed in human plasma (Figure 1). ${ }^{12}$ Preclinical and pharmacological studies with aclidinium have demonstrated low systemic availability and a low propensity to induce cardiac arrhythmias, ${ }^{11-13}$ and these findings have been reflected in a safety and tolerability profile that is similar to placebo in larger clinical trials. ${ }^{14-19}$ Due to the rapid hydrolysis of aclidinium in plasma, the kidney plays little role in clearance of the drug and urinary excretion is very low. ${ }^{20}$ Consistent with this, there is no relationship between the degree of renal impairment and aclidinium plasma exposure. ${ }^{20}$

Here, we report data pooled from 6 placebo-controlled

\section{Figure 1. Aclidinium is Rapidly Hydrolyzed in Human Plasma (in vitro study) ${ }^{12}$}

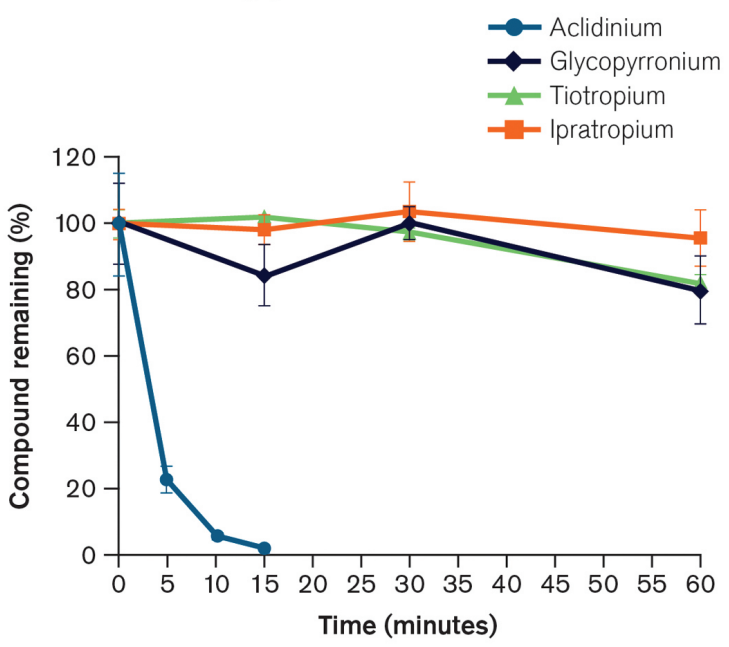

Data are mean \pm standard deviation from three independent experiments

Reprinted from Pulm Pharmacol Ther, 28 (2), Gavaldà A, Ramos I, Carcasona C, et al. The in vitro and in vivo profile of aclidinium bromide in comparison with glycopyrronium bromide, pages 114-121, Copyright (C) (2014), with permission from Elsevier. 
Phase III studies of at least 1 month's treatment duration and evaluate the overall and CV safety of aclidinium $400 \mu \mathrm{g}$ administered twice daily (BID) in patients with moderate to severe COPD.

\section{Methods}

Safety data were pooled from the placebo and aclidinium $400 \mu \mathrm{g}$ BID arms of 6 multinational, multicenter, randomized, double-blind, parallel-group studies designed to assess the efficacy and safety of aclidinium in patients with COPD (Table 1). Aclidinium and placebo were administered in the morning and evening via a breath-actuated multidose DPI (Genuair ${ }^{\mathrm{TM}} /$ Pressair $^{\mathrm{B} a}$ ). All studies were conducted in accordance with the Declaration of Helsinki, International Conference on Harmonization/Good Clinical Practice Guidelines and local regulations. The studies were approved by the relevant institutional review board or independent ethics committee at each study center.

\section{Study Populations}

Eligible patients were males or females aged $\geq 40$ years

\section{Table 1. Study Designs}

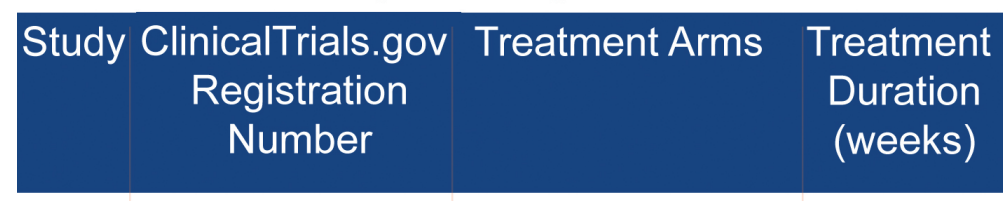

$1 \quad$ NCT01462929

Aclidinium $400 \mu \mathrm{g}$ BID

\begin{tabular}{c|c|c} 
Tiotropium $18 \mu \mathrm{g}$ QD & 6 \\
Placebo & \\
\hline
\end{tabular}

\begin{tabular}{|c|c|c|c|}
\hline 2 & NCT00891462 & Aclidinium $400 \mu \mathrm{g}$ BID & 12 \\
\hline 3 & NCT01001494 & Aclidinium $200 \mu \mathrm{g}$ BID & 24 \\
\hline 4 & NCT01045161 & Placebo & $12^{\mathrm{a}}$ \\
\hline
\end{tabular}

\begin{tabular}{|c|c|c|c|}
\hline \multirow{6}{*}{$\begin{array}{l}5 \\
6\end{array}$} & \multirow{7}{*}{$\begin{array}{l}\text { NCT01462942 } \\
\text { NCT01437397 }\end{array}$} & Aclidinium $400 \mu \mathrm{g}$ BID & \multirow{7}{*}{$\begin{array}{c}24 \\
24 / 28^{b}\end{array}$} \\
\hline & & Formoterol $12 \mu \mathrm{g}$ BID & \\
\hline & & Aclidinium/formoterol & \\
\hline & & FDC $400 / 12 \mu \mathrm{g}$ BID & \\
\hline & & Aclidinium/formoterol & \\
\hline & & FDC 400/6 $\mu \mathrm{g}$ BID & \\
\hline & & Placebo & \\
\hline
\end{tabular}

${ }^{a}$ Aclidinium bromide $200 \mu \mathrm{g}$ and $400 \mu \mathrm{g}$ BID compared with placebo over 12 weeks (double-blind), followed by evaluation of open-label aclidinium $400 \mu \mathrm{g}$ over 40 weeks; only the 12 -week double-blind period was used for the pooled analyses

${ }^{\text {bStudy }} 6$ was a 24-week study followed by a 28 -week extension

BID: twice daily; FDC: fixed-dose combination; QD: once daily of age who were current or former smokers ( $\geq 10$ pack years) diagnosed with moderate to severe COPD (post-bronchodilator forced expiratory volume in 1 second $\left[\mathrm{FEV}_{1}\right] /$ forced vital capacity ratio $<70 \%$; post-bronchodilator $\mathrm{FEV}_{1} \geq 30 \%$ and $<80 \%$ predicted normal).

Key exclusion criteria included: respiratory infection or COPD exacerbation $\leq 6$ weeks pre-screening ( $\leq 3$ months if hospitalized for exacerbations); presence or history of clinically significant respiratory conditions other than COPD (e.g., asthma); and presence or history of clinically significant CV conditions, including myocardial infarction ( $\leq 6$ months), newly diagnosed arrhythmia ( $\leq 3$ months), unstable angina or unstable arrhythmia requiring changes in pharmacological therapy ( $\leq 12$ months; Study $6 \leq 6$ months) and hospitalization for heart failure, functional class III or IV, as per New York Heart Association Guidelines ( $\leq 12$ months $) \cdot{ }^{21}$

Inhaled salbutamol (100 $\mu \mathrm{g} / \mathrm{puff})$ was permitted as rescue medication, provided its use was discontinued 6 hours before planned study visits. Inhaled corticosteroids, oral or parenteral corticosteroids ( $\leq 10 \mathrm{mg} /$ day of prednisone or $20 \mathrm{mg}$ every other day), oral sustained-release methylxanthines and oxygen therapy (<15 hours/day) were allowed, provided treatment was stable for $\geq 4$ weeks before screening. The use of other long-acting bronchodilators was prohibited.

\section{Safety Outcomes}

Patients were asked to report AEs in a patient diary on a daily basis between scheduled visits. Study physicians assessed the seriousness of the AEs at each study visit. AEs of special interest were analyzed based on the following standard Medical Dictionary for Regulatory Activities queries (Standardized MedDRA Queries [SMQs]): ischemic heart disease (including $\mathrm{SMQs}$ of myocardial infarction and other ischemic heart disease), tachyarrhythmia (and the following preferred terms [PTs]: tachycardia, heart rate increase, palpitations), bradyarrhythmia (nonspecific terms and the following PTs: sinus arrest and sinus bradycardia), conduction defects and cardiac failure. For anticholinergic events the anticholinergic syndrome SMQ was used in addition to other PTs of relevance, due to the mechanism of action. ${ }^{b}$ Lower respiratory tract infections, including pneumonia, were also investigated (High Level Term of lower 
respiratory tract and lung infections and additional PT of pneumonia). Additionally, cerebrovascular events were identified from the following SMQs: hemorrhagic and ischemic cerebrovascular conditions. Major adverse $\mathrm{CV}$ events (MACE), defined as the composite of CV deaths, non-fatal myocardial infarctions (SMQ: myocardial infarction) and non-fatal strokes (SMQs: hemorrhagic and ischemic cerebrovascular conditions), were also evaluated. Additional safety assessments were clinical laboratory tests, vital signs, electrocardiograms and Holter monitoring.

A sub-analysis of cardiac and cerebrovascular events was performed in patients with CV risk factors (cardiac disease, obesity [body mass index $\geq 30 \mathrm{~kg} /$ $\mathrm{m}^{2}$ ], hypertension, dyslipidemia or hyperglycemia/new onset diabetes mellitus). Additionally, a sub-analysis of AEs in patients with renal impairment was performed. In Studies 2-6, the degree of renal impairment was determined based on creatinine clearance (mild to severe: $\leq 80 \mathrm{~mL} / \mathrm{min}$; moderate to severe: $\leq 50 \mathrm{~mL} / \mathrm{min}$ ).
As creatinine levels were not assessed in Study 1, the higher level term 'renal failure and impairment' was used to identify patients with renal impairment; these cases were considered moderate to severe because mild cases are difficult to diagnose.

Safety outcomes were analyzed using descriptive statistics in the safety population (all randomized patients who received $\geq 1$ dose of study medication). Rate ratios (RR) were adjusted for exposure time using the Mantel-Hanszel formula.

\section{Results}

\section{Patients}

Of 2796 randomized patients, 2781 were included in the pooled safety population. In total, 474 patients $(17.0 \%)$ discontinued treatment, the primary reasons being withdrawal of consent (4.3\%), AEs (4.0\%) and lack of efficacy (2.5\%). Patient flow and the reasons for discontinuation are presented by treatment group in Figure 2. Patient demographics and baseline

\section{Figure 2. Diagram of Patient Flow}

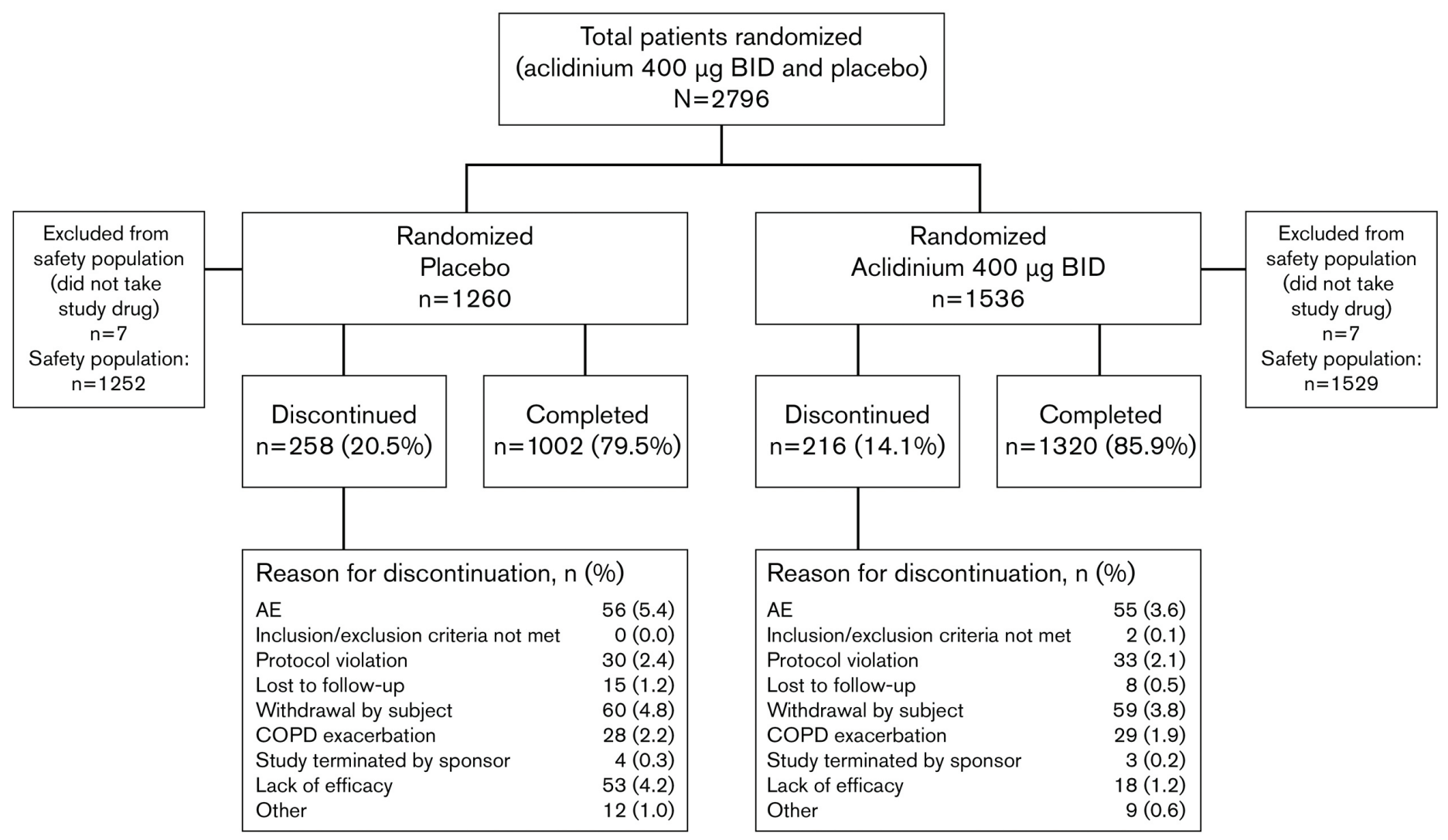

AE: adverse event; BID: twice daily; COPD: chronic obstructive pulmonary disease 
characteristics were similar between the treatment groups (Table 2). Overall, 23.8\% of patients had a history of cardiac disorders and $51.4 \%$ had a history of vascular disorders, as expected for this population.

\section{Table 2. Patient Demographics and Characteristics (Pooled Safety Population of Six Studies)}

\begin{tabular}{|c|c|c|}
\hline & $\begin{array}{l}\text { Placebo } \\
(\mathrm{n}=1252)\end{array}$ & $\begin{array}{c}\text { Aclidinium } \\
400 \mu g \text { BID } \\
(n=1529)\end{array}$ \\
\hline Mean Age, years (SD) & $63.2(8.7)$ & $63.4(8.6)$ \\
\hline Gender, male, \% & 59.6 & 60.8 \\
\hline Current Smoker, \% & 51.4 & 49.9 \\
\hline Mean $\mathrm{FEV}_{1}, \%$ predicted (SD) & $49.0(14.3)$ & $48.3(14.0)$ \\
\hline \multicolumn{3}{|l|}{ COPD Severity, \% } \\
\hline Moderate & 60.4 & 59.2 \\
\hline Severe & 39.0 & 40.5 \\
\hline \multicolumn{3}{|l|}{ Key CV-related Medical History, \% } \\
\hline Cardiac Disorders & 22.0 & 25.2 \\
\hline Coronary Artery Disease & 7.1 & 7.7 \\
\hline Myocardial Infarction & 4.2 & 4.7 \\
\hline Myocardial Ischemia & 3.2 & 3.3 \\
\hline Heart Failure & 2.4 & 2.7 \\
\hline Atrial Fibrillation & 2.2 & 2.5 \\
\hline Vascular Disorders & 51.8 & 51.1 \\
\hline Hypertension & 48.0 & 45.9 \\
\hline \multicolumn{3}{|l|}{ Key Concomitant Medications, \% } \\
\hline ACE Inhibitors, plain & 21.5 & 23.0 \\
\hline ACE Inhibitors, combinations & 3.8 & 3.3 \\
\hline Angiotensin II Antagonists, plain & 7.3 & 6.3 \\
\hline Antithrombotic Agents & 27.4 & 27.7 \\
\hline Beta-blocking Agents & 14.7 & 13.9 \\
\hline Lipid-modifying Agents, plain & 29.5 & 28.2 \\
\hline $\begin{array}{l}\text { Selective } \mathrm{Ca}^{2+} \text { Channel Blockers } \\
\text { with direct cardiac effects }\end{array}$ & 3.2 & 1.6 \\
\hline $\begin{array}{l}\text { Selective } \mathrm{Ca}^{2+} \text { Channel Blockers } \\
\text { with mainly vascular effects }\end{array}$ & 4.4 & 4.3 \\
\hline \multicolumn{3}{|l|}{ Sub-analysis Populations } \\
\hline $\begin{array}{l}\text { Patients With Any CV Risk Factor, } \\
\mathrm{n}(\%)\end{array}$ & $739(59.0)$ & $868(56.8)$ \\
\hline $\begin{array}{l}\text { Patients With Mild to Severe Renal } \\
\text { Impairment, } \mathrm{n}(\%)\end{array}$ & $532(42.5)$ & $459(30.0)$ \\
\hline $\begin{array}{l}\text { Patients With Moderate to Severe } \\
\text { Renal Impairment, n (\%) }\end{array}$ & $65(5.2)$ & $83(5.4)$ \\
\hline
\end{tabular}

ACE: angiotensin-converting enzyme; BID, twice daily; $\mathrm{Ca}^{2+}$ : calcium ion; COPD: chronic obstructive pulmonary disease; CV:

cardiovascular; $\mathrm{FEV}_{1}$ : forced expiratory volume in 1 second; SD: standard deviation
In total, 1607 patients had CV risk factors and were included in the CV risk factor sub-analysis. The subanalyses in patients with renal impairment included 991 patients with mild to severe renal impairment and 148 patients with moderate to severe renal impairment.

\section{Overall Safety}

The incidence of AEs, including cardiac and cerebrovascular AEs, was comparable with aclidinium $400 \mu \mathrm{g}$ and placebo (Table 3). A similar proportion of patients with aclidinium $400 \mu \mathrm{g}$ and placebo reported $\mathrm{AEs}$ (including $\mathrm{CV}$ and cerebrovascular AEs) leading to discontinuation (Table 3). There were 7 deaths (0.5\%) in the aclidinium $400 \mu \mathrm{g}$ group and $4(0.3 \%)$ in the placebo group (Table 3).

\section{Anticholinergic Events}

The incidence of possible anticholinergic AEs with aclidinium $400 \mu \mathrm{g}$ was low $(<2 \%)$ and comparable to placebo (Table 4). The most commonly reported AEs that were potentially anticholinergic in nature were urinary tract infection and oropharyngeal pain.

\section{Major Adverse Cardiovascular Events (MACE)}

There was no difference between the aclidinium 400 $\mu \mathrm{g}$ and placebo groups for the incidence of MACE AEs (Figure $3 \mathrm{a}$ ) and SAEs (Figure $3 \mathrm{~b}$ ). The total incidence of MACE across treatment groups was low (AEs: 0.7\%; SAEs: $0.5 \%$ ). None of the $3 \mathrm{CV}$ deaths that occurred across the 6 studies were considered to be related to treatment by the investigators.

\section{Table 3. Summary of Total AEs, AEs Leading to Discontinuation and Deaths}

\begin{tabular}{lrr} 
AE, $n(\%)$ & $\begin{array}{r}\text { Placebo } \\
(\mathrm{n}=1252)\end{array}$ & $\begin{array}{c}\text { Aclidinium } \\
400 \mu \mathrm{\mu g} \text { BID } \\
(\mathrm{n}=1529)\end{array}$ \\
\hline Total AEs & $693(55.4)$ & $818(53.5)$ \\
\hline Any Cardiac Event & $55(4.4)$ & $76(5.0)$ \\
\hline Any Cerebrovascular Event & $6(0.5)$ & $6(0.4)$ \\
\hline AEs Leading to Discontinuation & $77(6.2)$ & $80(5.2)$ \\
\hline Any Cardiac Event & $10(0.8)$ & $12(0.8)$ \\
\hline Any Cerebrovascular Event & $1(0.1)$ & $2(0.1)$ \\
\hline Deaths & $4(0.3)$ & $7(0.5)$ \\
\hline CV deaths & $1(0.1)$ & $2(0.1)$ \\
\hline
\end{tabular}

AE: adverse event; BID: twice daily; CV: cardiovascular 


\section{Table 4. Summary of Anticholinergic AEs Reported by $\geq 2$ Patients in Any Treatment Group}

\begin{tabular}{|c|c|c|}
\hline $\mathrm{AE}, \mathrm{n}(\%)$ & $\begin{array}{l}\text { Placebo } \\
(n=1252)\end{array}$ & $\begin{array}{c}\text { Aclidinium } \\
400 \mu \mathrm{g} \text { BID } \\
(\mathrm{n}=1529)\end{array}$ \\
\hline Urinary Tract Infection & $25(2.0)$ & $29(1.9)$ \\
\hline Oropharyngeal Pain & $23(1.8)$ & $20(1.3)$ \\
\hline Constipation & $13(1.0)$ & $15(1.0)$ \\
\hline Dry Mouth & $6(0.5)$ & $12(0.8)$ \\
\hline Pyrexia & $6(0.5)$ & $12(0.8)$ \\
\hline Dizziness & $13(1.0)$ & $11(0.7)$ \\
\hline Pharyngitis & 7 (0.6) & $9(0.6)$ \\
\hline Throat Irritation & 7 (0.6) & $4(0.3)$ \\
\hline Cystitis & $3(0.2)$ & $4(0.3)$ \\
\hline Tachycardia & $0(0.0)$ & $9(0.6)$ \\
\hline Dysphonia & $0(0.0)$ & $7(0.5)$ \\
\hline SV Tachycardia & $2(0.2)$ & $3(0.2)$ \\
\hline Dysuria & $2(0.2)$ & $3(0.2)$ \\
\hline Palpitations & $2(0.2)$ & $4(0.3)$ \\
\hline Ventricular Tachycardia & $1(0.1)$ & $2(0.1)$ \\
\hline Laryngitis & $3(0.2)$ & $2(0.1)$ \\
\hline Presyncope & $2(0.2)$ & $2(0.1)$ \\
\hline Sinus Tachycardia & $1(0.1)$ & $3(0.2)$ \\
\hline Somnolence & $1(0.1)$ & $2(0.1)$ \\
\hline Urinary Incontinence & $2(0.2)$ & $0(0.0)$ \\
\hline Urinary Retention & $0(0.0)$ & $2(0.1)$ \\
\hline
\end{tabular}

\section{Cardiac and Cerebrovascular Events}

The incidence of cardiac and cerebrovascular events based on SMQ categories was low (AEs: $\leq 2 \%$ in each category; $S A E s: \leq 0.6 \%$ in each category) and comparable between the aclidinium $400 \mu \mathrm{g}$ and placebo groups (Figure 4 and Table 5). Furthermore, the incidence of cardiac and cerebrovascular events was generally similar for patients with CV risk factors who received aclidinium compared with those who received placebo (aclidinium: 67 [7.7\%], incidence rate per 1000 patientyears: 182.6; placebo: 53 [7.2\%], incidence rate per 1000 patient-years: 191.9 ; RR [95\% confidence interval $(C I)]=1.01[0.74,1.39])$. In the subset of patients with mild to severe renal impairment, the incidence of cardiac events was similar with aclidinium and placebo (aclidinium: 27 [5.9\%], incidence rate per 1000 patient- years: 120.5; placebo: 31 [5.8\%], incidence rate per 1000 patient-years: 146.6 ; RR $[95 \% \mathrm{CI}]=0.87$ [0.56, 1.36]). Similarly, in patients with moderate to severe renal impairment, the incidence of cardiac events was comparable with aclidinium and placebo (aclidinium: 4 [4.8\%], incidence rate per 1000 patient-years: 113.2; placebo: 3 [4.6\%], incidence rate per 1000 patientyears: 114.7 ; RR $[95 \% \mathrm{CI}]=0.53[0.17,1.67])$.

\section{Lower Respiratory Tract Infections}

The incidence of any lower respiratory tract infection was low and similar between the 2 treatment groups (AEs: aclidinium: 32 [2.1\%]; placebo: 36 [2.9\%]; SAEs: aclidinium: 6 [0.4\%]; placebo: 9 [0.7\%]). Similarly, the incidence of pneumonia was comparable with aclidinium and placebo (AEs: aclidinium: 9 [0.6\%]; placebo: 11 [0.9\%]; SAEs: aclidinium: 6 [0.4\%]; placebo: 8 [0.6\%]).

\section{Discussion}

This pooled analysis of 6 placebo-controlled Phase III studies suggests that aclidinium $400 \mu \mathrm{g}$ BID has a good safety profile, with no evidence of increased CV or cerebrovascular risk compared with placebo in patients with moderate to severe COPD. Furthermore, sub-analyses showed that the incidence of cardiac and cerebrovascular events was similar with aclidinium and placebo in patients with CV risk factors and there was no evidence for a difference in the incidence of cardiac events between treatment groups in patients with mild to severe renal impairment.

There has been controversy surrounding the CV safety of anticholinergics since a meta-analysis of 17 randomized clinical trials reported a significantly increased risk of major CV events (relative risk 1.58) with inhaled anticholinergics (tiotropium or ipratropium via mist inhaler, DPI or metered dose inhaler) compared with control therapy (placebo or active comparator) in patients with COPD; however, the difference in all-cause mortality with inhaled anticholinergics compared with controls did not reach significance (relative risk 1.26; $p=0.06) .{ }^{22}$ Subsequent reports of tiotropium safety compared with placebo have varied, with a 4-year study of tiotropium via DPI showing a trend towards decreased all-cause mortality and no change in CV events ${ }^{5}$ and a second meta-analysis of tiotropium via mist inhaler reporting a $52 \%$ increase in all-cause mortality and an increased risk of $\mathrm{CV}$ death. ${ }^{4}$ Studies comparing 


\section{Figure 3. Major Adverse Cardiovascular Events a) AEs and b) SAEs (Pooled Safety Population From Six Studies)}

a) $A E s^{a}$

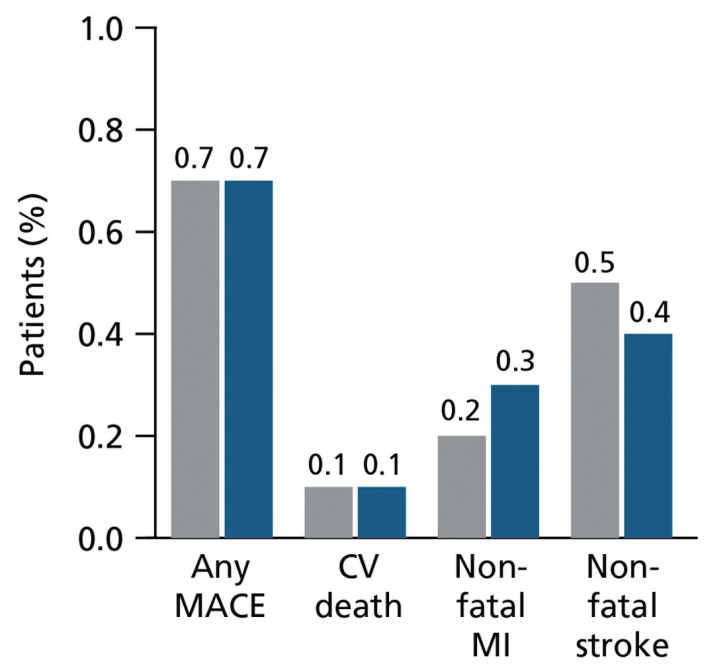

b) SAEs

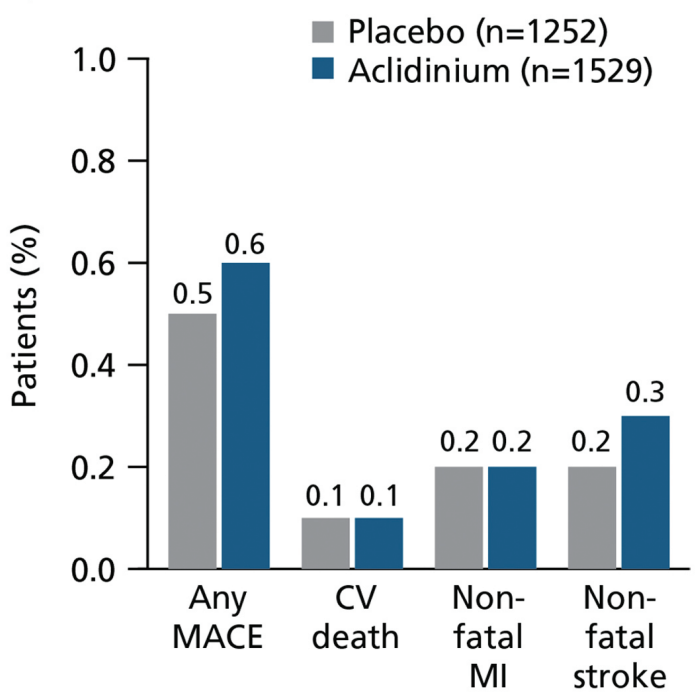

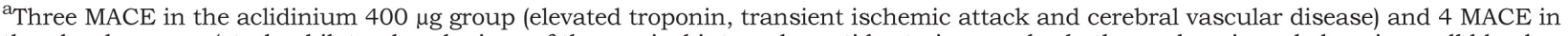
the placebo group (stroke, bilateral occlusions of the cervical internal carotid arteries, cerebral atherosclerosis and chronic small blood vessel ischemia in the brain) were not considered SAEs by the investigators.

${ }^{b}$ SAEs are a subset of the AEs
}

AE: adverse event; CV: cardiovascular; MACE: major adverse CV event; MI: myocardial infarction; SAE: serious adverse event

\section{Figure 4. Cardiac and Cerebrovascular AEs (Pooled Safety Population From Six Studies)}

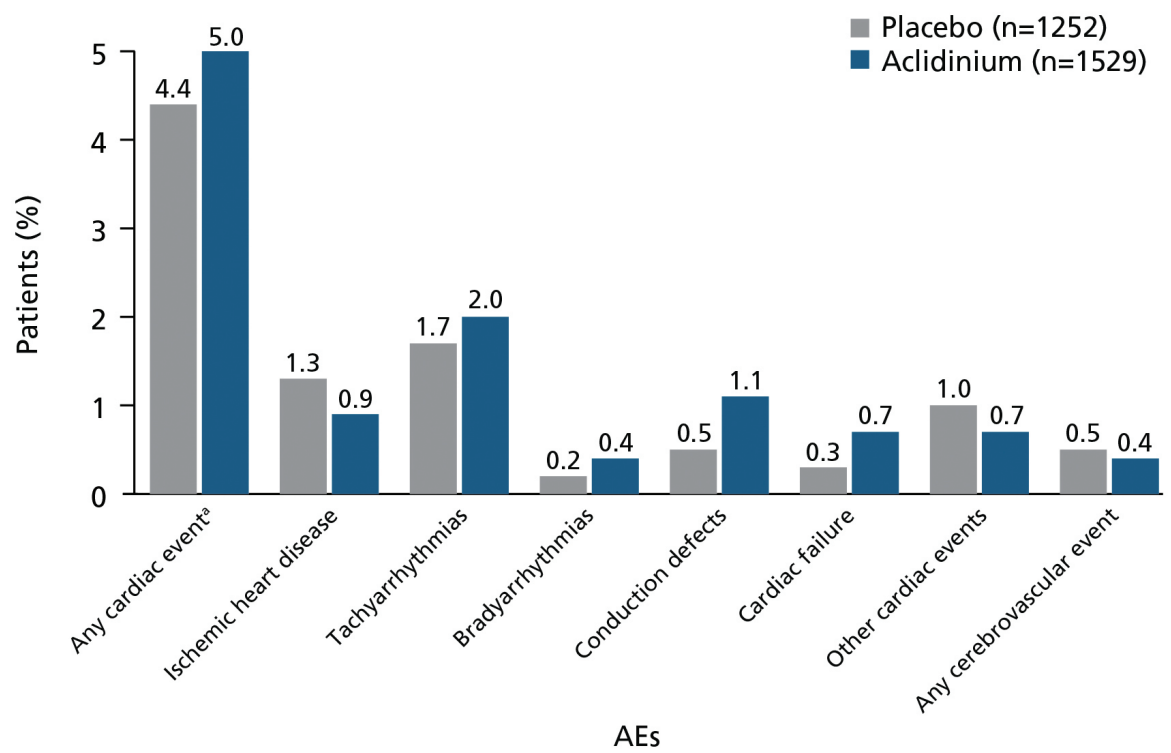

${ }^{\mathrm{a}}$ Increased heart rate also included (from investigations of SOC)

AE: adverse event; SAE: serious adverse event; SOC: system organ class mortality between the 2 tiotropium formulations have been inconclusive, with some studies suggesting mortality is higher with the mist inhaler compared with the $\mathrm{DPI}^{2,3}$ and others finding no difference between the 2 formulations. ${ }^{6}$

The baseline characteristics of the study population in our pooled analysis are similar to those of the 2011 meta-analysis, ${ }^{4}$ with comparable mean age (63.2-63.4 years versus 63.0-65.7 years), a slightly lower degree of airflow limitation (mean FEV 1 48.3-49.0\% versus $37.5-42.0 \%$ predicted normal) and proportion of male patients (59.6-60.8\% versus 69.0-79.3\%), and a slightly greater proportion of current smokers (49.9$51.4 \%$ versus $35.0-43.0 \%$ ).

One of the limitations of this pooled analysis is that since CV safety was not the primary outcome 


\section{Table 5. Summary of Cardiac and Cerebrovascular SAEs}

\begin{tabular}{|c|c|c|}
\hline SAE, n (\%) & $\begin{array}{l}\text { Placebo } \\
(n=1252)\end{array}$ & $\begin{array}{c}\text { Aclidinium } \\
400 \mu g \text { BID } \\
(n=1529)\end{array}$ \\
\hline Any Cardiac Event ${ }^{a}$ & $13(1.0)$ & $17(1.1)$ \\
\hline Ischemic Heart Disease & $7(0.6)$ & $6(0.4)$ \\
\hline Myocardial Infarction & $3(0.2)$ & $4(0.3)$ \\
\hline Other Ischemic Heart Disease & $4(0.3)$ & $2(0.1)$ \\
\hline Tachyarrhythmias ${ }^{\mathrm{b}}$ & $4(0.3)$ & $2(0.1)$ \\
\hline Atrial Fibrillation & $4(0.3)$ & $1(0.1)$ \\
\hline Palpitations & $0(0.0)$ & $1(0.1)$ \\
\hline Tachycardia & $0(0.0)$ & $0(0.0)$ \\
\hline Bradyarrhythmias & $0(0.0)$ & $0(0.0)$ \\
\hline Conduction Defects & $0(0.0)$ & $0(0.0)$ \\
\hline Cardiac Failure & $2(0.2)$ & $5(0.3)$ \\
\hline Other Cardiac Events & $2(0.2)$ & $4(0.3)$ \\
\hline Sick Sinus Syndrome & $1(0.1)$ & $1(0.1)$ \\
\hline Arrhythmia & $1(0.1)$ & $0(0.0)$ \\
\hline Cardiac Discomfort & $0(0.0)$ & $1(0.1)$ \\
\hline Cardio-Respiratory Arrest & $0(0.0)$ & $1(0.1)$ \\
\hline Any Cerebrovascular Event & $3(0.2)$ & $4(0.3)$ \\
\hline \multicolumn{3}{|c|}{$\begin{array}{l}\text { Increased heart rate also included (from standard of care } \\
\text { investigations) }\end{array}$} \\
\hline \multicolumn{3}{|c|}{${ }^{\mathrm{b}}$ Palpitations in aclidinium $400 \mu \mathrm{g}$ also reported as SAE } \\
\hline
\end{tabular}

in any of the 6 clinical trials, all of the pooled safety data used in the analysis were collected from patient reports, in which AEs and SAEs were spontaneously reported to the physician by the patient. However, if the study physician observed a clinically relevant abnormality in clinical laboratory tests, vital signs or electrocardiogram/Holter recordings, this was to be reported as an AE/SAE. A further limitation was that none of the studies were enriched with high-risk patients, such as those with clinically significant CV disease or renal insufficiency. Indeed, TIOSPIR also excluded high-risk patients, as have many of the other studies investigating the efficacy and safety of LAMAs. 4,6,23,24 A recent post-hoc analysis of the UPLIFT trial, however, found that patients with cardiac comorbidities were not at increased risk of mortality or cardiac SAEs with tiotropium $18 \mu \mathrm{g}$ once daily versus placebo. ${ }^{25}$ The ongoing Evaluate the Effect of Aclidinium Bromide on Long-term Cardiovascular Safety and Exacerbations in Moderate to Very Severe COPD Patients: ASCENT COPD (NCT01966107) double-blind, randomized, placebo-controlled Phase IV study is investigating the

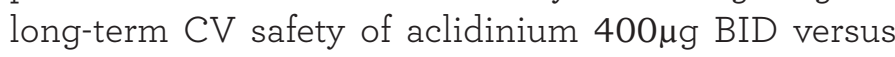
placebo in patients with moderate to very severe COPD and significant $\mathrm{CV}$ comorbidities. ${ }^{26}$ However, there is still a need to conduct longer-term head-to-head studies of LAMAs, including all available formulations, as well as studies in "real-world" patients with common comorbidities, in order to fully evaluate and compare the safety profile.

Although the 2011 meta-analysis raised concerns about the safety of tiotropium via mist inhaler, we have shown that in a similar patient population, aclidinium has an overall and CV safety profile comparable to placebo. To date, there have been no head-to-head comparator studies of aclidinium and tiotropium via mist inhaler. However, aclidinium and tiotropium via DPI have been evaluated in a 6-week, randomized, placebo- and activecontrolled Phase III study, in which the incidence of AEs was similar with aclidinium (27.5\%) and tiotropium (29.7\%). ${ }^{14}$ The incidence of potentially anticholinergic AEs was $<1.5 \%$ in both treatment groups. ${ }^{14}$

In vitro studies have shown that aclidinium is rapidly hydrolyzed into 2 inactive metabolites in human plasma and has a shorter half-life than tiotropium, glycopyrronium and ipratropium (Figure 1). ${ }^{12,13}$ This property of aclidinium may help to minimize cardiac events. A study in dogs, in which rapid plasma hydrolysis of aclidinium also occurs, showed that aclidinium had a reduced effect on heart rate compared with tiotropium when administered at doses that were 100-fold higher than those needed for bronchodilation. ${ }^{11}$ Rapid hydrolysis of aclidinium also minimizes systemic exposure and, consequently, the potential for systemic side effects. ${ }^{12,13}$ Systemic side effects are a particular concern for patients with CKD, as renal impairment can reduce drug clearance and increase systemic exposure. Recent United Kingdom data suggest the prevalence of CKD is higher in the COPD population (Stage 3-5 CKD: $18.2 \%$ ) than in the general adult population (Stage 3-5 CKD: 8.5\%). ${ }^{27}$ Verhamme and colleagues have shown evidence for increased mortality with tiotropium via mist inhaler compared with tiotropium via DPI in patients with renal impairment, with a $27 \%$ increased risk of death in patients who received tiotropium via mist inhaler compared with those who received the drug via DPI. ${ }^{28}$ When the data were stratified by level of renal impairment, the association between the use of the mist inhaler and mortality remained significant in patients with Stage 3-5 CKD but not in those with normal kidney 
function. ${ }^{9}$ Renal clearance of aclidinium is very low in both patients with mild to severe renal impairment and patients with normal renal function. ${ }^{20}$ In patients with normal kidney function, $0.090 \%$ of the aclidinium dose is recovered from urine ${ }^{20}$ compared with $60.1 \%$ of the tiotropium dose. ${ }^{29}$ The low urinary excretion of aclidinium may make it suitable for patients with CKD. Indeed, the results from this pooled analysis suggest there are no increased safety risks in patients with renal impairment. However, it is important to highlight that in this pooled analysis, the number of patients with renal impairment - particularly those with moderate to severe renal impairment - was relatively low.

In conclusion, aclidinium $400 \mu \mathrm{g}$ BID has a good safety profile with no evidence of increased $\mathrm{CV}$ or cerebrovascular risk compared with placebo. The safety profile of aclidinium and its rapid plasma hydrolysis suggest it can be used safely in patients with comorbidities, including patients with CV disease and $\mathrm{CKD}$. However, further studies are needed to assess the

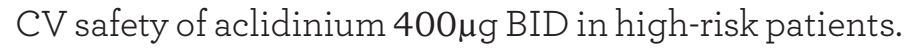

aRegistered trademark of AstraZeneca group of companies; for use within the USA as Pressair ${ }^{\circledR}$ and as Genuair ${ }^{T M}$ within all other licensed territories.

${ }^{b}$ Sinus tachycardia, supraventricular tachycardia, ventricular tachycardia, heart rate increased, palpitations, angle closure glaucoma, glaucoma, mydriasis, intraocular pressure increased, intraocular pressure test abnormal, papillary reflex impaired, pupils unequal, visual disturbance, accommodation disorder, blindness transient, cyclopegia, constipation, gastrointestinal obstruction, ileus paralytic, urinary tract infection, cystitis urinary retention, urinary incontinence, incontinence, dysuria, urge incontinence, urine flow decreased, bladder irritation, oropharyngeal pain, dysphonia, laryngitis, pharyngitis and throat irritation.

\section{Acknowledgments}

The authors would like to thank Rosa Lamarca for assistance with statistical analyses and the study investigators at each of the participating centers for their contribution to the studies.

\section{Declaration of Interest}

KRC has received grants from Almirall, Forest Laboratories, Novartis, GlaxoSmithKline, Boehringer Ingelheim, AstraZeneca, Roche, Genentech, Amgen, Grifols and CSL Behring. EB has no conflicts of interest to disclose. DA is a former employee of Almirall, S.A., Barcelona, Spain. EGG is an employee of AstraZeneca PLC, Barcelona, Spain and a former employee of Almirall, S.A., Barcelona, Spain. The sponsor, Almirall S.A., Barcelona, Spain, was involved in the design and conduct of the analysis, review of the data, and review and approval of the manuscript; AstraZeneca also reviewed the manuscript. Medical writing support, funded by AstraZeneca, was provided by Suzanne McAllister, PhD, of Complete Medical Communications. 


\section{References}

1. Global initiative for chronic Obstructive Lung Disease (GOLD). Global strategy for the diagnosis, management and prevention of chronic obstructive pulmonary disease. GOLD website. http:// www.goldcopd.com/guidelines-global-strategy-for-diagnosismanagement.html. Updated January 2014. Accessed November 12, 2014.

2. Dong YH, Lin HH, Shau WY, et al. Comparative safety of inhaled medications in patients with chronic obstructive pulmonary disease: systematic review and mixed treatment comparison meta-analysis of randomised controlled trials. Thorax. 2013; 68(1):48-56. doi:http://dx.doi.org/10.1136/thoraxjnl-2012-201926

3. Karner C, Chong J, Poole P. Tiotropium versus placebo for chronic obstructive pulmonary disease. Cochrane Database Syst Rev. 2012; 7:CD009285. doi: http://dx.doi.org/10.1002/14651858.cd009285.pub2

4. Singh S, Loke YK, Enright PL, Furberg CD. Mortality associated with tiotropium mist inhaler in patients with chronic obstructive pulmonary disease: systematic review and meta-analysis of randomised controlled trials. BMJ. 2011; 342:d3215. doi: http://dx.doi.org/10.1136/bmj.d3215

5. Celli B, Decramer M, Kesten S, et al. Mortality in the 4-year trial of tiotropium (UPLIFT) in patients with chronic obstructive pulmonary disease. Am J Respir Crit Care Med. 2009; 180(10):948-955.

doi: http://dx.doi.org/10.1164/rccm.200906-08760C

6. Wise RA, Anzueto A, Cotton D, et al. Tiotropium Respimat inhaler and the risk of death in COPD. N Engl J Med. 2013; 369:14911501. doi: http://dx.doi.org/10.1056/NEJMoa1303342

7. Divo M, Cote C, de Torres JP, et al. Comorbidities and risk of mortality in patients with chronic obstructive pulmonary disease. Am J Respir Crit Care Med. 2012; 186(2):155-161. doi: http://dx.doi.org/10.1164/rccm.201201-0034OC

8. Mullerova H, Agusti A, Erqou S, Mapel DW. Cardiovascular comorbidity in COPD: systematic literature review. Chest. 2013; 144(4):1163-1178.

doi: http://dx.doi.org/10.1378/chest.12-2847

9. Verhamme KM, van Blijderveen N, Sturkenboom MC. Tiotropium and the risk of death in COPD. N Engl J Med. 2014; 370:481-482.

10. Wise RA. Tiotropium and the risk of death in COPD. $N$ Engl $J$ Med. 2014; 370:482.

11. Gavaldà A, Miralpeix M, Ramos I, et al. Characterization of aclidinium bromide, a novel inhaled muscarinic antagonist, with long duration of action and a favorable pharmacological profile. J Pharmacol Exp Ther. 2009; 331(2):740-751.

doi: http://dx.doi.org/10.1124/jpet.109.151639

12. Gavaldà A, Ramos I, Carcasona C, et al. The in vitro and in vivo profile of aclidinium bromide in comparison with glycopyrronium bromide. Pulm Pharmacol Ther. 2014;28(2):114 121. doi: http://dx.doi.org/10.1016/j.pupt.2014.05.005

13. Sentellas S, Ramos I, Albertí J, et al. Aclidinium bromide, a new, long-acting, inhaled muscarinic antagonist: in vitro plasma inactivation and pharmacological activity of its main metabolites. Eur J Pharm Sci. 2010; 39:283-290.

doi: http://dx.doi.org/10.1016/j.ejps.2010.01.004
14. Beier J, Kirsten AM, Mróz R, et al. Efficacy and safety of aclidinium bromide compared with placebo and tiotropium in patients with moderate-to-severe chronic obstructive pulmonary disease: results from a 6-week, randomized, controlled Phase IIIb study. COPD. 2013; 10(4):511-522.

doi: http://dx.doi.org/10.3109/15412555.2013.814626

15. D'Urzo A, Kerwin E, Rennard S, et al. One-year extension study of ACCORD COPD I: safety and efficacy of two doses of twicedaily aclidinium bromide in patients with COPD. COPD. 2013; 10(4):500-510. doi: http://dx.doi.org/10.3109/15412555.2013.791809

16. Gelb AF, Tashkin DP, Make BJ, et al. Long-term safety and efficacy of twice-daily aclidinium bromide in patients with COPD. Respir Med. 2013; 107(12):1957-1965. doi:http://dx.doi.org/10.1016/j.rmed.2013.07.001

17. Jones PW, Singh D, Bateman ED, et al. Efficacy and safety of twice-daily aclidinium bromide in COPD patients: the ATTAIN study. Eur Respir J. 2012; 40(4):830-836. doi: http://dx.doi.org/10.1183/09031936.00225511

18. Kerwin EM, D'Urzo AD, Gelb AF, et al. Efficacy and safety of a 12-week treatment with twice-daily aclidinium bromide in COPD patients (ACCORD COPD I). COPD. 2012; 9(2):90-101. doi: http://dx.doi.org/10.3109/15412555.2012.661492

19. Rennard SI, Scanlon PD, Ferguson GT, et al. ACCORD COPD II: a randomized clinical trial to evaluate the 12-week efficacy and safety of twice-daily aclidinium bromide in chronic obstructive pulmonary disease patients. Clin Drug Investig. 2013; 33(12):893904. doi:http://dx.doi.org/10.1007/s40261-013-0138-1

20. Schmid K, Pascual S, Garcia Gil E, et al. Pharmacokinetics and safety of aclidinium bromide, a muscarinic antagonist, in adults with normal or impaired renal function: A phase I, open-label, single-dose clinical trial. Clin Ther. 2010; 32(10):1798-1812. doi: http://dx.doi.org/10.1016/j.clinthera.2010.09.002

21. New York Heart Association. Classes of heart failure. American Heart Association website. http://www.heart.org/HEARTORG/ Conditions/HeartFailure/AboutHeartFailure/Classes-of-HeartFailure_UCM_306328_Article.jsp\# Updated April 6, 2015. Accessed December 15, 2015.

22. Singh $S$, Loke $Y K$, Furberg $C D$. Inhaled anticholinergics and risk of major adverse cardiovascular events in patients with chronic obstructive pulmonary disease: a systematic review and metaanalysis. JAMA. 2008; 300(12):1439-1450.

doi: http://dx.doi.org/10.1001/jama.300.12.1439

23. D’Urzo A, Ferguson GT, van Noord JA, et al. Efficacy and safety of once-daily NVA237 in patients with moderate-to-severe COPD: the GLOW1 trial. Respir Res. 2011; 12:156. doi: http://dx.doi.org/10.1186/1465-9921-12-156

24. Kerwin E, Hébert J, Gallagher N, et al. Efficacy and safety of NVA237 versus placebo and tiotropium in patients with COPD: the GLOW2 study. Eur Respir J. 2012; 40(5):1106-1114. doi: http://dx.doi.org/10.1183/09031936.00040712

25. Tashkin DP, Leimer I, Metzdorf N, Decramer M. Cardiac safety of tiotropium in patients with cardiac events: a retrospective analysis of the UPLIFT(R) trial. Respir Res. 2015; 16:65. doi: http://dx.doi.org/10.1186/s12931-015-0216-4 
26. Wise RA. Evaluation of major adverse cardiovascular events and COPD exacerbations in a long-term study of aclidinium bromide in patients with moderate to very severe COPD: ASCENT COPD rationale and design. Am J Respir Crit Care Med. 2014; 189.

27. Price D, Davis E, Gilchrist A, West D. Prevalence of chronic kidney disease (CKD) in the UK COPD population. Eur Respir J. 2014; 44 (Suppl. 58): 1939.

28. Verhamme KM, Afonso A, Romio S, et al. Use of tiotropium Respimat $^{\circledR}$ SMI vs. tiotropium Handihaler ${ }^{\circledR}$ and mortality in patients with COPD. Eur Respir J. 2013; 42(3):606-615. doi: http://dx.doi.org/10.1183/09031936.00005813

29. Turck D, Weber W, Sigmund R, et al. Pharmacokinetics of intravenous, single-dose tiotropium in subjects with different degrees of renal impairment. J Clin Pharmacol. 2004; 44(2):163172. doi: http://dx.doi.org/10.1177/0091270003261315 